\title{
Teacher and School Characteristics Associated with the Identification and Referral of Adolescent Depression and Oppositional Defiant Disorders by U.S. Teachers
}

\author{
Jennifer Greif Green ${ }^{1}\left[\right.$ [ $\cdot$ Rachel Oblath $^{2} \cdot$ Melissa Holt $^{1}$
}

Accepted: 26 November 2021 / Published online: 14 January 2022

(c) The Author(s), under exclusive licence to Springer Science+Business Media, LLC, part of Springer Nature 2021

\begin{abstract}
Teachers contribute to the process of identifying and referring students for mental health services, however, relatively little is known about how they make those decisions and how decision-making differs across school contexts. This study used a vignette-based method to investigate individual and school contextual factors associated with the likelihood that teachers identify and refer students for mental health services. Teachers were recruited from public middle and high schools across the U.S. using a stratified random sampling strategy. Teachers $(N=462)$ responded to vignettes by indicating their concern for students, as well as their likelihood of providing mental health referrals. Vignettes varied by problem type (depression, oppositional defiant disorder), problem severity (moderate, severe), and student gender (male, female). Data on school characteristics were extracted from the U.S. Department of Education database. Regression models indicated several significant associations of teacher demographic characteristics and school characteristics with vignette ratings. For example, female teachers were more likely than males to rate vignettes as concerning, and middle school teachers were more likely than high school teachers to indicate they would refer students for mental health services. Teachers in schools with a higher proportion of Black students rated depression vignettes as less serious and indicated they were less likely to refer students for mental health services than teachers in majority white schools. Results suggest school characteristics may contribute to established disparities in mental health service access. Findings have implications for targeting mental health supports in schools.
\end{abstract}

Keywords Adolescents · Schools $\cdot$ Mental health services $\cdot$ Disparities

\section{Introduction}

Studies are clear that there are high rates of unmet need for mental health care among U.S. children and adolescents with emotional and behavioral disorders. For example, results from the National Comorbidity Survey Adolescent Supplement (NCS-A) suggest that $70 \%$ of youth with a 12-month

Jennifer Greif Green

jggreen@bu.edu

Rachel Oblath

roblath@bu.edu

Melissa Holt

holtm@bu.edu

1 Wheelock College of Education and Human Development, Boston University, 2 Silber Way, Boston, MA 02115, USA

2 Department of Psychiatry, Boston Medical Center, Boston, MA, USA disorder do not receive any mental health services (Merikangas et al. 2010b, 2011) and these results are consistent with rates found in other studies in the U.S. and internationally (Benjet et al., 2016; Kovess-Masfety et al., 2017; Leaf et al., 1996; Sheppard et al., 2018; Whitney \& Peterson, 2019). Research also indicates that the adolescents who use mental health services most often receive those services within their schools (Costello et al., 2014; Duong et al., 2021) or outside of school as the result of a referral from school staff (Burns et al., 1995). As such, schools serve as key settings for reducing unmet need for mental health services, both through on-site service provision and through identification and referral to treatment. Furthermore, schools have the potential to reduce some of the common barriers to accessing community-based mental health services described by youth (e.g., cost, transportation; Gulliver et al., 2010).

The current study focuses on the identification and referral decisions of teachers, as teachers interact with youth regularly and are well-positioned to notice disorders early 
in their course and to provide referrals to students (Aitken et al., 2017; Brown et al., 2006; De Los Reyes et al., 2015). Moreover, teachers have the potential to contribute to reducing inequities in mental health service access by referring students for services who might not otherwise access community-based services. In particular, studies of communitybased mental health service use indicate disparities in access related to symptom type (e.g., youth with behavior disorders more often receive services than those with anxiety or depression), ethnicity/race (e.g., non-Latinx white students more often receive services than youth of color), and gender (e.g., gender-related differences in service use vary with symptom type; Alegría et al., 2016; Costello et al., 2014). These inequities, in part, reflect the referral decision-making process of teachers, parents, and other adults interacting daily with youth (Alegría et al., 2012). Identifying the factors that influence teacher referral decisions can have implications for improving youth access to mental health services.

\section{Teachers' Role in the Referral Process}

The role of teachers in referral decisions can be conceptualized using the Gateway Provider Model (Stiffman et al., 2004), which posits that youth access to mental health services relies upon "gateway providers" who identify a need for services and make decisions about whether to connect youth with appropriate resources. Studies have found that decision-making by providers is influenced by a combination of characteristics of youth (e.g., need for those services, demographic characteristics), factors enabling service access (e.g., availability, acceptability), structural characteristics (e.g., organizational and management factors), and the provider's own perceptions and knowledge of mental health and mental health resources (Stiffman et al., 2004).

Several studies have tested aspects of the Gateway Provider Model and found that teacher identification of youth with emotional and behavioral disorders indeed varies as a function of student problem type, race/ethnicity, and gender (Chang \& Sue, 2003; Green et al., 1996; Loades \& Mastroyannopoulou, 2010; Splett et al., 2020). For example, studies have found that teachers are less likely to identify youth of color than their non-Latinx white peers as needing mental health supports and are less likely to encourage youth of color to use those services (Alegría et al., 2012; Chang \& Sue, 2003; Lau et al., 2003). These studies suggest that bias in the referral process may contribute to well-established racial and ethnic disparities in access to mental health services (Costello et al., 2014). Further, studies have shown that clinicians are more likely to diagnosis Black youth with disruptive behavior disorders than their white peers, whereas white youth more often receive diagnoses and services for internalizing disorders (Gudiño et al., 2009; Nguyen et al., 2007). These trends may also help explain why youth of color are more often subjected to exclusionary disciplinary practices (e.g., suspensions and expulsions) and less often access appropriate mental health services than their white peers (Skiba et al., 2011). Understanding how teachers conceptualize and respond to internalizing behaviors, in contrast to acting out behaviors, can provide key information about differential decision-making for mental health referrals. In particular, when teachers identify student behavior as being problematic, rather than indicative of a problem, students may be less likely to receive needed care. Teacher preconceptions about students and their behaviors may therefore be even more salient than actual need for services, when it comes to decision-making around mental health referrals (Stiffman et al., 2004).

In addition to student characteristics, several studies have highlighted teacher characteristics associated with referral decisions. For example, teacher ratings of student behavior have been found to be linked to the teachers' own experiences of burnout and self-efficacy (McLean et al., 2019). In addition, a study by Splett et al. (2020) found significant between-teacher variance in teacher ratings of student behavior, with greater variance in ratings of internalizing than externalizing behaviors. This result suggests that the likelihood of students receiving a needed referral is dependent upon characteristics of their teacher, a finding that is consistent with data showing that teachers-in-training in the U.S. tend to receive little to no instruction in social emotional wellbeing or identification of mental health problems as part of teacher preparation (Reinke et al., 2011; State et al., 2011). Without such preparation, teachers are left to rely on their own understanding of mental health, and often describe relying on indicators of academic challenges rather than mental health symptoms (Bradshaw et al., 2008; Green et al., 2017).

Studies, however, have rarely tested how characteristics of the school context are associated with teacher referrals to mental health services. Understanding how individual and contextual factors jointly influence teacher decision-making about mental health referrals can have important implications for determining structural changes needed to improve access to mental health services for youth (Ringeisen et al., 2003). For example, identifying school characteristics associated with mental health referrals can provide information about how to situate teacher professional development in context, and can be used to generate hypotheses about structural influences on individual teacher decision-making.

\section{Current Study}

The current study uses a vignette-based approach to investigate patterns in teacher identification and referral of students with depression and oppositional defiant disorder (ODD). These two disorders were selected as examples of 
internalizing (depression) and externalizing (ODD) problems that are common among adolescents and often have first onset in adolescent years (Merikangas et al., 2010a, 2010b; Nock et al., 2007), which means that middle and high school teachers have the potential to identify them early in their course. Further, these diagnoses offer a contrast between behaviors that are often identified for mental health services (depression) and those that may become the subject of exclusionary discipline practices rather than a mental health referral (ODD).

Vignette-based approaches have been used in previous studies to test characteristics associated with teacher mental health referrals (Chang \& Sue, 2003; M.T. Green et al., 1996; J.G. Green et al., 2018; Loades \& Mastroyannopoulou, 2010; Splett et al., 2020). Vignettes have the advantage of providing a standardized scenario, which researchers can systematically vary, allowing researchers to isolate and test particular factors that may influence decision-making. In the current study, we use vignettes to examine whether reported level of concern about students and likelihood of referral for mental health services vary as a function of individual student factors (disorder type, disorder severity, student gender). In addition, and consistent with the Gateway Provider Model (Stiffman et al., 2004), we examine the association of teachers' reported level of concern and likelihood of referral with teacher characteristics (e.g., gender, years of experience), and school organizational characteristics (e.g., urbanicity, racial/ethnic composition of the student body).

The current study examines teacher identification and referral patterns among a U.S. sample of middle and high school teachers. Prior studies of teacher identification patterns have focused almost entirely on elementary school teachers (Chang \& Sue, 2003; Green et al., 1996; Loades \& Mastroyannopoulou, 2010; Pearcy et al., 1993; Splett et al., 2020; Weisz et al., 1988). The few exceptions are studies of middle and high school teachers that have used geographically limited samples (Green et al., 2018) or studied only one problem type (i.e., depression; Jorm et al., 2010). However, investigating teachers' role in mental health referrals during adolescence is particularly important because disorders increase precipitously in adolescence (Merikangas et al., 2010a, 2010b). At the same time, adolescence presents particular challenges to teacher involvement in identification and referral for mental health services, because adolescents often rotate between classrooms throughout the school day and teachers therefore may have less contact with individual students than at the elementary level. Nonetheless, some researchers have found that adolescents, and particularly adolescents of color, are more likely to access mental health services when their families are encouraged to seek out services by adults they know, including teachers (Alegría et al., 2012).
Using a sample of U.S. middle and high school teachers, and vignettes reflecting one internalizing disorder (depression) and one externalizing disorder (oppositional defiant disorder), we answer the following questions:

1. What student, teacher, and school characteristics are associated with teacher identification of depression, concern about a student with depression, and likelihood of referral for mental health services?

2. What student, teacher, and school characteristics are associated with teacher concern about a student with oppositional defiant disorder, and likelihood of referral for mental health services?

This study contributes to the existing literature by (a) providing information about teacher identification and mental health referrals specifically for adolescents, (b) using a sample of teachers across the U.S., which allows testing for regional differences, and (c) examining school-level contextual factors that may have implications for structural change. Identifying characteristics associated with teachers' concern for students and likelihood of mental health service referral has the potential to provide information about how factors unrelated to need may influence gateway provider referrals. These characteristics can become important leverage points for teacher training and educational policy, as they may indicate pathways that underscore inequities in service access.

\section{Method}

\section{Participants}

A list of all U.S. public schools was downloaded from the Department of Education website. The list was narrowed to middle and high schools, and schools were then stratified by region of the country and urbanicity. Schools within each strata were randomly selected for participation using a random number generator, with an oversampling of schools in large cities. Research assistants went to the website of each randomly selected school and searched for a publicly available list of teacher email addresses. If there was no publicly available list of teacher email addresses, we went to the next randomly selected school. When an email list was publicly available, we randomly selected the email address of one general education teacher, using a random number generator. Each teacher was sent a postcard informing them of the study and that they would be receiving a subsequent email invitation to participate. Teachers then received an email with an online invitation to complete the web-survey. Teachers who did not respond to the initial invitation were sent up to two follow-up emails. If that teacher did not respond to our invitation, we sent a survey by mail. If we still received 
no response, we randomly selected a second person from the same school to contact. If they did not respond to the same series of contact attempts, we went to the next randomly selected school.

In total, because of this process of replacing and re-selecting teachers, 1386 teachers were invited to participate in the study. Those who participated in the online survey were sent a $\$ 15$ gift card. Those who did not respond to the email invitations received a survey by mail, along with a $\$ 5$ gift card and a stamped return envelope. If they returned the completed survey, they were mailed a second $\$ 10$ gift card to receive the full incentive amount. A total of 501 teachers completed the survey either online $(n=322,64.3 \%)$ or by mail $(n=179,35.7 \%)$ representing a $36.1 \%$ response rate. Analyses included only teachers who provided complete data for at least one vignette ( $n=460$ for the depression vignette and $n=462$ for the ODD vignette).

Teachers were evenly distributed across the four regions of the country (Northeast, 27.3\%; Midwest, 26.8\%; South, 19.3\%; West, 22.7\%). Consistent with U.S. national data (Taie \& Goldring, 2017), teachers primarily identified as female and non-Latinx White (see Table 1 for sample demographics and Table S1 for a comparison on the current sample to US national data). The Boston University Institutional Review Board approved all study procedures.

\section{Measures}

\section{Vignette Construction}

Vignettes used in the current study (see Table 2) were adapted from vignettes developed by the Center for Multicultural Mental Health Research to study parent perceptions of child need for mental health services (Chavez et al., 2010). Initial development of vignettes is described in more detail elsewhere (Lapatin et al., 2012). We selected vignettes that focused on one internalizing disorder (depression) and one externalizing disorder [oppositional defiant disorder (ODD)].

As described elsewhere (Green et al., 2018), 19 teachers participated in focus groups during summer 2014 to review the vignettes. Teachers' feedback on the vignettes was used to modify the text (for example, teachers suggested focusing on information that would be observable in a classroom setting, removing information about family and home-life, and adding information about academic performance). Final vignettes were 100-130 words in length with symptom descriptions based on criteria from the Diagnostic and Statistical Manual of Mental Disorders (American Psychiatric Association, 2013). We used scenarios that depicted "moderate" disorders and then modified those scenarios to include information to identify the disorders as "severe." For example, for the vignette characterizing depression, the student in the "moderate" version of the vignette seems moody, puts their head down on their desk, has lost interest in activities they used to enjoy, and has trouble concentrating in class. In the "severe" version, the student has additionally missed school, and the teacher overhears them saying "I'm totally worthless."

\section{Validity of Vignettes}

Vignette validity was initially assessed using expert ratings. As described in more detail elsewhere (Green et al., 2018), 14 clinical and research experts in child or adolescent mental health rated the vignettes. On a scale of 1-10 (where 1 was "not at all realistic" and 10 was "very realistic") experts gave the vignettes an average rating of $8.7(\mathrm{SD}=1.3)$. As in Lapatin et al., (2012) we next asked experts to use the Children's Global Assessment Scale (C-GAS; Shaffer et al., 1983) to rate impairment experienced by students in vignettes (on a scale of $0-100$, with lower scores indicating greater impairment). These ratings enabled us to calibrate the severity of vignettes (i.e., ensure that the severity of the depression and ODD vignettes were similar, and that the moderate vignettes were rated as less severe than the severe vignettes). Each expert rated two to four vignettes, providing a total of 34 vignette ratings. There were no significant differences between C-GAS ratings of depression $(M=51.5, \mathrm{SD}=10.4)$ and $\mathrm{ODD}(M=53.8, \mathrm{SD}=9.0)$ vignettes $(t(32)=-0.72$, $p=0.48)$. Experts rated moderate vignettes as significantly less impaired $(M=56.8, \mathrm{SD}=8.6)$ than severe vignettes $(M=47.9, \mathrm{SD}=8.4 ; t(30)=3.04, p<0.01)$.

Vignettes were then sent to 500 school psychologists randomly selected from the National Association of School Psychologists (NASP) mailing list. One hundred school psychologists returned the survey (20\% response rate). On a scale of 1 to 10 (where 1 was "not at all realistic" and 10 was "very realistic") school psychologists rated the vignettes an average of $8.4(\mathrm{SD}=1.5)$. School psychologists also used the C-GAS to rate the impairment of students in vignettes. We used these severity ratings to validate the manipulation of the moderate vs. severe versions of the vignettes. Each school psychologist completed two vignette ratings (depression and ODD), providing a total of 200 ratings. There were no significant differences between C-GAS ratings of depression $(M=50.7, \mathrm{SD}=9.9)$ and $\mathrm{ODD}(M=52.0, \mathrm{SD}=10.8)$ vignettes $\left(t_{(191)}=0.8, p=0.40\right)$. School psychologists rated moderate vignettes as significantly less impaired $(M=54.5$, $\mathrm{SD}=11.3)$ than severe vignettes $(M=48.1, \mathrm{SD}=8.2$; $\left.t_{(191)}=4.5, p<0.001\right)$.

\section{Procedure}

We systematically varied the type of disorder (depression, ODD), severity of disorder (moderate, severe), and gender 
Table 1 Individual teacher characteristics and school characteristics $(N=462)$

\begin{tabular}{|c|c|}
\hline Individual teacher characteristics & Number (\%) \\
\hline \multicolumn{2}{|l|}{ Gender } \\
\hline Male & $143(31.0 \%)$ \\
\hline Female & $307(66.5 \%)$ \\
\hline Other/missing & $12(2.6 \%)$ \\
\hline \multicolumn{2}{|l|}{ Ethnicity } \\
\hline Hispanic/Latinx & $22(4.8 \%)$ \\
\hline Not Hispanic/Latinx & $440(95.2 \%)$ \\
\hline \multicolumn{2}{|l|}{ Race $^{1}$} \\
\hline White/Caucasian & $411(89.0 \%)$ \\
\hline Black/African American & $23(5.0 \%)$ \\
\hline Asian/Asian American & $6(1.3 \%)$ \\
\hline Native Hawaiian/Other Pacific Islander & $1(0.2 \%)$ \\
\hline American Indian/Alaska Native & $3(0.6 \%)$ \\
\hline Other & $14(3.0 \%)$ \\
\hline \multicolumn{2}{|l|}{ Years teaching } \\
\hline Mean (SD) & $15.0(9.2)$ \\
\hline School characteristics $^{1}$ & Number $(\%)$ \\
\hline \multicolumn{2}{|l|}{ School level } \\
\hline Middle & $220(48.9 \%)$ \\
\hline High & $230(51.1 \%)$ \\
\hline \multicolumn{2}{|l|}{ Type of school ${ }^{2}$} \\
\hline Public & $431(93.3 \%)$ \\
\hline Private & $4(0.9 \%)$ \\
\hline Alternative & $6(1.3 \%)$ \\
\hline Charter & $42(9.1 \%)$ \\
\hline Magnet & $24(5.2 \%)$ \\
\hline Other & $10(2.2 \%)$ \\
\hline \multicolumn{2}{|l|}{ Region of the country } \\
\hline Northeast & $126(27.3 \%)$ \\
\hline South & $89(19.3 \%)$ \\
\hline Mid-West & $124(26.8 \%)$ \\
\hline West & $105(22.7 \%)$ \\
\hline \multicolumn{2}{|l|}{ Urbanicity } \\
\hline City & $238(51.5 \%)$ \\
\hline Suburb & $79(17.1 \%)$ \\
\hline Town & $82(17.7 \%)$ \\
\hline Rural & $61(13.2 \%)$ \\
\hline \multicolumn{2}{|l|}{ Racial/ethnic composition } \\
\hline $50 \%$ or more White & $250(54.1 \%)$ \\
\hline $50 \%$ or more Black & $58(12.6 \%)$ \\
\hline $50 \%$ or more Hispanic/Latinx & $49(10.6 \%)$ \\
\hline No majority & $99(21.7 \%)$ \\
\hline \multicolumn{2}{|l|}{ Title I school } \\
\hline Yes & $313(69.1 \%)$ \\
\hline No & $140(30.9 \%)$ \\
\hline \multicolumn{2}{|l|}{ Number of students } \\
\hline Mean in school (SD) & $795.9(596.0)$ \\
\hline \multicolumn{2}{|l|}{ FTE classroom teachers } \\
\hline Mean in school (SD) & $48.7(33.5)$ \\
\hline
\end{tabular}

${ }^{1}$ Sample sizes varied due to missing data

${ }^{2}$ Multiple responses could be selected, so percentages add to more than $100 \%$ 
Table 2 Depression and oppositional defiant disorder vignettes

\begin{tabular}{|c|c|}
\hline Depression: moderate (male) & Oppositional defiant disorder: moderate (female) \\
\hline $\begin{array}{l}\text { David is a student in your class. He is always kind with other people } \\
\text { and follows instructions during class. In the last few months, David } \\
\text { has been increasingly moody, and you have noticed that he often } \\
\text { puts his head down on his desk. He also seems to have lost interest } \\
\text { in many of his friends and classwork, including participating in class } \\
\text { activities that he used to enjoy. Every day David says that he feels } \\
\text { very tired, but when you ask, he also says he is sleeping more than } \\
\text { normal at night. In addition, the last few months, David seems to } \\
\text { have trouble concentrating in class }\end{array}$ & $\begin{array}{l}\text { Anna is a student in your class. She has a longstanding group of friends, } \\
\text { of which she is the leader. Anna has above-average intelligence, is } \\
\text { very articulate, and has maintained good grades in school without } \\
\text { working hard. Over the past six months, Anna has started to lose her } \\
\text { temper a lot. She often appears angry, and she frequently blames oth- } \\
\text { ers for her mistakes. Lately Anna's friends have begun to stay away } \\
\text { from her because she is overly sensitive, becomes annoyed easily, and } \\
\text { at times she seems to try to annoy her friends on purpose. You have } \\
\text { noticed that Anna argues with you more than other students her age }\end{array}$ \\
\hline Depression: severe (female) & Oppositional defiant disorder: moderate (male) \\
\hline $\begin{array}{l}\text { Anna is a student in your class. She is always kind with other people } \\
\text { and follows instructions during class. In the last few months, Anna } \\
\text { has been increasingly moody, putting her head down on her desk. } \\
\text { Anna also seems to have lost interest in many of her friends and } \\
\text { classwork, including participating in activities that she used to enjoy. } \\
\text { Every day Anna says that she feels very tired, however, when you } \\
\text { ask, she also says that she is sleeping more than normal at night. As } \\
\text { a result, on some occasions she has missed school and lately seems } \\
\text { increasingly sad and hopeless. In the last few months, Anna seems to } \\
\text { have trouble concentrating on what she is doing during independent } \\
\text { work in your class. Recently, you heard Anna saying to her friends: } \\
\text { "I can't do anything right. I'm totally worthless!" }\end{array}$ & $\begin{array}{l}\text { David is a student in your class. He has a longstanding group of friends, } \\
\text { of which he is the leader. David is very articulate, and has maintained } \\
\text { good grades in school without working hard. In the last few months, } \\
\text { David has increasingly argued with his friends and put them down. He } \\
\text { often appears angry, and he frequently blames others for his mistakes. } \\
\text { David's friends have begun to stay away from him because he has } \\
\text { been overly sensitive, becomes annoyed easily, and at times he seems } \\
\text { to try to annoy his friends on purpose. David defies his teachers, and } \\
\text { he refuses to comply with adults' requests and rules. He argues loudly } \\
\text { with his teachers, more than other students in his classes. Recently, his } \\
\text { teachers have often had to place David in detention }\end{array}$ \\
\hline
\end{tabular}

Names were systematically varied to indicate student gender

(male, female) of students. The order in which vignettes were presented was randomized. As in a previous study (Chavez et al., 2010), we varied the names Anna and David to indicate gender. These names were selected because, as described in Lapatin et al. (2012), they are common names used in both English and Spanish and tend not to be associated with a single race or ethnicity, but tend to be associated with male or female gender. Teachers were not provided with student demographic information other than name (as a proxy for gender) and were asked to imagine that the student in the vignette was "a student in your class" in order to make age, race/ethnicity, and grade-level of students relevant to individual respondents and their own school context.

\section{Teacher Identification and Referral}

The survey included four measures of teacher identification of student mental health need and one measure of referral likelihood. To determine whether teachers would identify youth in the vignettes as requiring mental health services, teachers were asked to rate (1) the seriousness of the problem, (2) how worried about the problem they would be, and (3) how common the problem is among their students. These ratings were identical to those in the study by Chavez et al. (2010) and were completed using a 10-point scale (with anchors ranging from, for example, not at all serious to very serious). For the depression vignette, similar to Jorm et al. (2010), teachers were asked to describe "What, if anything, is going on with [Student name]?" Teachers who responded that the vignette described "depression" were coded as (4) identifying depression. This coding was conducted by undergraduate research assistants who were trained and reached reliability. While we asked the same question following the presentation of the ODD vignette, very few respondents $(n=4,0.8 \%)$ identified the behaviors as being associated with "ODD" or "oppositional defiant disorder" and we therefore did not construct an equivalent rating for identification for the ODD vignette to use in further analyses. In addition, (5) referral likelihood was measured by asking teachers to rate on a 10-point scale the likelihood that they would refer the student in the vignette to a mental health services provider.

\section{Individual Characteristics}

Teachers indicated their own gender identity, race, ethnicity, and number of years teaching.

\section{School Characteristics}

Data from the U.S. Department of Education Common Core of Data (https://nces.ed.gov/ccd/) were extracted to measure region of the country based on U.S. Census regions (Northeast, Midwest, South, West), school urbanicity (City, Suburb, Town, Rural), whether the school qualified for Title I funding, school level (middle, high), and student racial/ 
ethnic composition (percent of students identifying as Black, Hispanic/Latinx, and White). Racial/ethnic composition was further categorized as majority Black, majority Hispanic/ Latinx, and majority White, when $50 \%$ or more of students were identified as being of that race/ethnicity. Schools in which there was no majority were categorized as non-majority schools.

\section{Analytic Strategy}

A series of logistic and linear regressions were conducted to estimate the association of individual teacher and school characteristics with teacher identification of disorders (seriousness of the problem, worry about the problem, commonness, identification of depression) and likelihood of referral for services. The first series of models estimated bivariate associations between each individual teacher or school factor with each identification or referral variable. The second set of models tested the multivariate association of all individual teacher characteristics in one model, with each identification or referral variable. The third set of models tested the multivariate association of all school characteristics in one model, with each identification or referral variable. A final series of models, presented below, tested all individual teacher, and school characteristics together in one multivariate model. Models were estimated separately for depression and ODD vignettes and all models controlled for vignette gender and vignette severity. Subsequent analyses tested a series of interaction terms to identify whether individual teacher and school characteristics interacted with vignette gender and vignette severity in their association with identification and referral likelihood.

\section{Results}

\section{Depression}

Overall, $56.7 \%$ of the sample $(n=261)$ identified the depression vignette as referring to a student with depression. Teacher identification of depression and ratings of problem seriousness, worry about the student, commonness of the problem, and likelihood of referral varied significantly as a function of vignette factors, individual teacher characteristics, and school characteristics (Tables 3, 4). As expected, vignette severity was significantly associated with identification of depression $(\mathrm{OR}=2.4,95 \% \mathrm{CI}=1.5-3.9)$, higher ratings of problem seriousness $(B=0.8, \mathrm{SE}=0.2$, $b=0.3, p<0.001)$, more worry about the student $(B=0.7$, $\mathrm{SE}=0.2, b=0.3, p<0.001)$, rating the problem as less common $(B=-0.6, \mathrm{SE}=0.3, b=-0.1, p=0.024)$, and greater likelihood of referral for mental health services $(B=0.6$, $\mathrm{SE}=0.2, b=0.2, p=0.003)$. The only individual teacher characteristics associated with vignette ratings was gender; teachers who identified as female rated the vignette as more serious ( $B=0.5, \mathrm{SE}=0.2, b=0.2, p=0.003)$, worrisome $(B=0.5, \mathrm{SE}=0.2, b=0.2, p=0.002)$, and common $(B=0.7$, $\mathrm{SE}=0.3, b=0.2, p=0.006)$, than teachers who identified as male. In terms of school characteristics, high school teachers were more likely than middle school teachers to identify depression $(\mathrm{OR}=1.7,95 \% \mathrm{CI}=1.0-2.7)$, but reported a lower likelihood of referring the student for mental health services $(B=-0.5, \mathrm{SE}=0.2, b=-0.1, p=0.017)$. Teachers in the West region of the country indicated they were less likely to refer students than teachers in the Northeast $(B=-0.6, \mathrm{SE}=0.3, b=-0.1, p=0.046)$. Having a higher proportion of Black students in the school was associated with lower ratings of problem seriousness $(B=-1.0$, $\mathrm{SE}=0.4, b=-0.2, p=0.012)$ and decreased likelihood of referral for mental health services $(B=-1.3, \mathrm{SE}=0.5$, $b=-0.2, p=0.018$ ).

For each significant main effect, we tested whether teacher and school factors interacted with vignette gender or severity. The only significant interactions were related to teacher gender. First, there was a significant interaction of teacher gender with vignette gender, in association with ratings of problem seriousness $(B=-0.9, \mathrm{SE}=0.3, b=-0.3$, $p=0.005)$ and worry $(B=-0.9, \mathrm{SE}=0.3, b=-0.3$, $p=0.005)$. Specifically, female teachers rated female vignettes as more serious and worrisome and male vignettes as less serious and less worrisome than did male teachers. Second, there was a significant interaction of teacher gender and vignette severity with ratings of vignette seriousness $(B=-0.9, \mathrm{SE}=0.3, b=-0.3, p=0.008)$, such that female teachers rated moderate vignettes as more serious than did male teachers.

\section{Oppositional Defiant Disorder}

As noted above, only $0.8 \%$ of respondents $(n=4)$ specifically identified the ODD vignette as referring to a student with ODD. Teacher ratings of problem seriousness, worry about the student, commonness of the problem, and likelihood of referral of ODD vignettes varied significantly as a function of vignette factors, individual teacher characteristics, and school characteristics (Tables 5, 6). Teachers rated severe vignettes as significantly more serious $(B=0.5, \mathrm{SE}=0.2, b=0.2, p=0.004)$ and worrisome than moderate vignettes $(B=0.4, \mathrm{SE}=0.2, b=0.1, p=0.035)$. Female teachers were more likely to rate vignettes as serious $(B=0.3, \mathrm{SE}=0.2, b=0.1, p=0.045)$, worrisome $(B=0.4, \mathrm{SE}=0.2, b=0.1, p=0.035)$, and common $(B=0.8, \mathrm{SE}=0.3, b=0.2, p=0.002)$ than male teachers. High school teachers rated ODD vignettes as less common $(B=-0.6, \mathrm{SE}=0.3, b=-0.1, p=0.017)$ and reported that they were less likely to make a referral $(B=-0.7$, 
Table 3 Rates of teachers identifying depression and ratings of depression seriousness, worry, commonness, and likelihood of referral

\begin{tabular}{|c|c|c|c|c|c|}
\hline Teacher and school factors & $\begin{array}{l}\text { Depression } \\
\%\end{array}$ & $\begin{array}{l}\text { Serious } \\
M \text { (SD) }\end{array}$ & $\begin{array}{l}\text { Worry } \\
M(\mathrm{SD})\end{array}$ & $\begin{array}{l}\text { Common } \\
M(\mathrm{SD})\end{array}$ & $\begin{array}{l}\text { Referral } \\
M(\mathrm{SD})\end{array}$ \\
\hline \multicolumn{6}{|l|}{ Vignette factors } \\
\hline \multicolumn{6}{|l|}{ Vignette gender } \\
\hline Male & 55.1 & $8.2(1.4)$ & $8.3(1.4)$ & $4.3(2.2)$ & $8.5(1.9)$ \\
\hline Female & 58.7 & $8.2(1.4)$ & $8.2(1.3)$ & $4.4(2.1)$ & $8.6(1.8)$ \\
\hline \multicolumn{6}{|l|}{ Vignette severity } \\
\hline Moderate & 46.4 & $7.8(1.4)$ & $8.0(1.4)$ & $4.5(2.2)$ & $8.3(1.9)$ \\
\hline Severe & $66.8^{*}$ & $8.6(1.3)^{*}$ & $8.7(1.2)^{*}$ & $4.2(2.2)$ & $8.9(1.7)^{*}$ \\
\hline \multicolumn{6}{|l|}{ Teacher factors } \\
\hline \multicolumn{6}{|l|}{ Gender } \\
\hline Male & 47.6 & $7.9(1.5)$ & $7.9(1.4)$ & $4.1(2.1)$ & $8.4(1.8)$ \\
\hline Female & $60.9 *$ & $8.3(1.3)^{*}$ & $8.5(1.3)^{*}$ & $4.5(2.2)$ & $8.7(1.8)$ \\
\hline \multicolumn{6}{|l|}{ Ethnicity } \\
\hline Hispanic/Latinx & 59.1 & $8.6(1.3)$ & $8.7(1.2)$ & $3.9(2.2)$ & $9.2(1.1)$ \\
\hline Not Hispanic/Latinx & 56.8 & $8.2(1.4)$ & $8.3(1.4)$ & $4.4(2.2)$ & $8.6(1.8)^{*}$ \\
\hline \multicolumn{6}{|l|}{ Race } \\
\hline White/Caucasian & 57.7 & $8.2(1.4)$ & $8.3(1.4)$ & $4.3(2.2)$ & $8.6(1.8)$ \\
\hline Black/African American & 43.5 & $8.1(1.5)$ & $8.3(1.4)$ & $4.3(2.2)$ & $8.0(2.4)$ \\
\hline \multicolumn{6}{|l|}{ Other } \\
\hline \multicolumn{6}{|l|}{ Years teaching } \\
\hline$<10$ years teaching & 55.4 & $8.0(1.4)$ & $8.2(1.3)$ & $4.3(2.0)$ & $8.3(2.1)$ \\
\hline $10+$ years teaching & 57.7 & $8.3(1.4)$ & $8.4(1.4)$ & $4.3(2.2)$ & $8.7(1.7)^{*}$ \\
\hline \multicolumn{6}{|l|}{ School factors } \\
\hline \multicolumn{6}{|l|}{ School level } \\
\hline Middle & 52.1 & $8.2(1.5)$ & $8.3(1.4)$ & $4.1(2.1)$ & $8.8(1.5)$ \\
\hline High & 60.9 & $8.1(1.4)$ & $8.3(1.3)$ & $4.6(2.2)^{*}$ & $8.3(2.1)^{*}$ \\
\hline \multicolumn{6}{|l|}{ Type of school } \\
\hline Public & 56.5 & $8.2(1.4)$ & $8.2(1.2)$ & $5.0(2.5)$ & $8.6(1.8)$ \\
\hline Other & 62.1 & $8.2(1.4)$ & $8.4(1.4)$ & $4.3(2.1)$ & $8.5(1.5)$ \\
\hline \multicolumn{6}{|l|}{ Region of the country } \\
\hline Northeast & 56.3 & $8.3(1.4)$ & $8.4(1.4)$ & $4.3(2.0)$ & $8.8(1.8)$ \\
\hline South & 59.6 & $8.1(1.6)$ & $8.3(1.6)$ & $4.1(2.2)$ & $8.5(1.7)$ \\
\hline Mid-West & 58.9 & $8.1(1.4)$ & $8.4(1.3)$ & $4.5(2.3)$ & $8.4(2.0)$ \\
\hline West & 55.2 & $8.4(1.2)$ & $8.3(1.3)$ & $4.4(2.1)$ & $8.5(1.8)$ \\
\hline \multicolumn{6}{|l|}{ Urbanicity } \\
\hline City & 55.5 & $8.2(1.4)$ & $8.4(1.3)$ & $4.5(2.1)$ & $8.6(1.9)$ \\
\hline Suburb & 55.1 & $8.3(1.5)$ & $8.5(1.4)$ & $4.2(2.2)$ & $8.9(1.7)$ \\
\hline Town & 61.0 & $8.1(1.5)$ & $8.2(1.4)$ & $4.1(2.1)$ & $8.5(1.6)$ \\
\hline Rural & 59.0 & $8.1(1.3)$ & $8.3(1.4)$ & $4.1(2.2)$ & $8.4(2.0)$ \\
\hline \multicolumn{6}{|l|}{ Racial/ethnic composition } \\
\hline $50 \%$ or more White & 49.8 & $8.2(1.4)$ & $8.3(1.3)$ & $4.2(2.1)$ & $8.7(1.6)$ \\
\hline $50 \%$ or more Black & 46.2 & $7.8(1.6)^{* 1}$ & $8.1(1.5)$ & $5.2(2.2)^{* 2}$ & $7.9(2.5)^{* 3}$ \\
\hline $50 \%$ or more Hispanic/Latinx & 45.8 & $8.5(1.4)$ & $8.6(1.3)$ & $4.5(2.4)$ & $8.8(1.8)$ \\
\hline Non-majority & 60.7 & $8.3(1.2)$ & $8.5(1.3)$ & $4.0(2.0)$ & $8.6(1.8)$ \\
\hline \multicolumn{6}{|l|}{ Title I school } \\
\hline Yes & 55.1 & $8.2(1.5)$ & $8.4(1.4)$ & $4.5(2.2)$ & $8.5(1.9)$ \\
\hline No & 59.3 & $8.3(1.4)$ & $8.5(1.3)$ & $4.5(2.1)$ & $8.6(1.7)$ \\
\hline
\end{tabular}

${ }^{1}$ Majority Black < Majority Hispanic/Latinx

${ }^{2}$ Majority Black > Majority White and Non-Majority

${ }^{3}$ Majority Black < Majority Hispanic/Latinx and Majority White

${ }^{*} p<.05$ based on chi-square test, $\mathrm{t}$ test, or one-way ANOVA 
$\mathrm{SE}=0.3, b=-0.2, p=0.007)$ for mental health services than middle school teachers.

For each significant main effect, we tested whether individual and school factors interacted with vignette gender or severity. The only significant interaction was the interaction between the percent of Black students in the school and the severity of the vignette in relation to ratings of commonness of the problem $(B=2.5, \mathrm{SE}=0.9, b=-0.2, p=0.007)$. Specifically, in schools with a higher percent of Black students, teachers rated severe vignettes as significantly more common than did teachers in other schools.

\section{Discussion}

Understanding how teachers make decisions about mental health referrals has implications for practice and policy efforts that can target improved access to mental health services and decrease disparities in service access. Although researchers and policymakers have called for schools to conduct regular emotional and behavioral screenings, which are designed to identify any students who may need mental health supports (Auerbach et al., 2020; Briesch et al., 2018), estimates suggest that the actual usage of screenings in schools is quite low (e.g., 12.6\%; Bruhn et al., 2014). As such, in most schools, receipt of mental health services relies on students to initiate services themselves or on adults to facilitate the referral process. The role of teachers in these decisions has taken particular prominence in response to the COVID-19 pandemic, as the U.S. Department of Education has issued guidance that school and district leaders prioritize addressing student mental health needs and consider using federal funding to provide professional development for educators on this topic (U.S. Department of Education, 2021).

In the current sample, more than half $(56.7 \%)$ of teachers correctly identified a vignette describing depression, whereas only $0.8 \%$ of teachers correctly identified a vignette describing ODD. These results indicate that teachers are much more knowledgeable of the definition and symptoms of depression than ODD. Furthermore, our findings indicate that teacher ratings of concern for hypothetical students with depression and ODD are associated with vignette characteristics, as well as with individual teacher and school characteristics.

In terms of vignette characteristics, our finding that teachers rated severe vignettes as more concerning than moderate vignettes confirmed that our manipulation was effective and is also consistent with prior research finding that teachers effectively rate vignette severity (Loades \& Mastroyannopoulou, 2010; Splett et al., 2020). We found no differences in ratings of concern based on student gender. Epidemiologic studies finding that girls are more likely to receive mental health services for depression and males are more likely to receive mental health services for oppositional defiant disorder (Merikangas et al., 2011) suggest that gender differences would be expected. Some prior studies have also found that teachers are more likely to recognize and refer vignettes of boys with externalizing problems and girls with internalizing problems, as compared with when gender and problem-type pairs are reversed (Green et al., 1996; Loades \& Mastroyannopoulou, 2010). However, consistent with our findings, other vignette studies have found that student gender is not significantly associated with teacher ratings of need for intervention either in or out of school (Pearcy et al., 1993; Splett et al., 2020).

Our analysis of teacher characteristics found that female teachers consistently indicated greater concern about the students in the vignettes than did male teachers, though female and male teachers were equally likely to indicate that they would refer students for mental health services. We were unable to find any previous studies that tested the association of teacher gender with concern for student mental health or referral for services. However, this finding was generally consistent with prior research indicating that adult females have higher rates of mental health literacy than males (Cotton et al., 2006; Reavley et al., 2012). There was also a significant interaction of teacher gender with vignette gender in predicting ratings of depression vignette seriousness. The finding that female teachers were more concerned than male teachers about female students, and less concerned than male teachers about male students, supports the importance of attending to teacher-student demographic match in decisionmaking about supports and services for youth. Further, there was an interaction of teacher gender with depression vignette severity indicating that female teachers were more concerned than male teachers about moderate depression vignettes. In general, moderate vignettes are more ambiguous than severe vignettes (which were rated as highly concerning by both male and female teachers) and suggests that, for less clear cases of psychological distress, female teachers may be more likely to express concern.

Finally, three school characteristics were associated with teacher ratings: school level (middle vs. high), region of the country, and racial/ethnic composition of the school. First, as compared to teachers in middle schools, teachers in high schools were more likely to identify student depression correctly and to rate ODD as less common. These findings may be related to the different age of onset of the two disorders. ODD generally starts at a younger age (Nock et al., 2007) than depression (Merkinagas et al., 2010a; b; Kessler et al., 2005), therefore high school teachers may have greater knowledge of depression symptoms than do middle school teachers. Further, although ODD tends to start at a younger age, some studies have found a decline in prevalence of ODD in late childhood and early adolescence (Maughan et al., 2004), which is consistent with high school teachers 
Table 4 Depression:

Association between individual teacher characteristics, school characteristics, and indicators of identifying depression, ratings of seriousness, worry, commonness, and likelihood of referral

\begin{tabular}{|c|c|c|c|c|c|}
\hline Teacher and school factors & $\begin{array}{l}\text { Depression } \\
\text { OR }(95 \% \mathrm{CI})\end{array}$ & $\begin{array}{l}\text { Serious } \\
B(\mathrm{SE} B)\end{array}$ & $\begin{array}{l}\text { Worry } \\
B(\operatorname{SE~} B)\end{array}$ & $\begin{array}{l}\text { Common } \\
B(\mathrm{SE} B)\end{array}$ & $\begin{array}{l}\text { Referral } \\
B(\mathrm{SE} B)\end{array}$ \\
\hline \multicolumn{6}{|l|}{ Vignette factors } \\
\hline \multicolumn{6}{|l|}{ Vignette gender } \\
\hline Male & $1.0(0.6-1.6)$ & $0.2(0.2)$ & $0.1(0.2)$ & $-0.1(0.3)$ & $-0.1(0.2)$ \\
\hline \multicolumn{6}{|l|}{ Vignette severity } \\
\hline Severe & $2.4 *(1.5-3.9)$ & $0.8 *(0.2)$ & $0.7 *(0.2)$ & $-0.6^{*}(0.3)$ & $0.6^{*}(0.2)$ \\
\hline \multicolumn{6}{|l|}{ Teacher factors } \\
\hline \multicolumn{6}{|l|}{ Gender } \\
\hline Female & $1.1(0.7-1.8)$ & $0.5^{*}(0.2)$ & $0.5^{*}(0.2)$ & $0.7 *(0.3)$ & $0.1(0.2)$ \\
\hline \multicolumn{6}{|l|}{ Ethnicity } \\
\hline Hispanic/Latinx & $1.3(0.4-4.1)$ & $0.3(0.4)$ & $0.3(0.4)$ & $-0.3(0.6)$ & $0.8(0.5)$ \\
\hline \multicolumn{6}{|l|}{ Race } \\
\hline Black/African American & $0.4(0.1-1.1)$ & $-0.2(0.4)$ & $-0.1(0.4)$ & $0.4(0.6)$ & $-0.6(0.5)$ \\
\hline \multicolumn{6}{|l|}{ Years teaching } \\
\hline Years teaching (continuous) & $1.0(1.0-1.0)$ & $0.0(0.0)$ & $0.0(0.0)$ & $0.0(0.0)$ & $0.0(0.0)$ \\
\hline \multicolumn{6}{|l|}{ School factors } \\
\hline \multicolumn{6}{|l|}{ School level } \\
\hline High & $1.7 *(1.0-2.7)$ & $0.1(0.2)$ & $0.1(0.2)$ & $0.3(0.3)$ & $-0.5 *(0.2)$ \\
\hline \multicolumn{6}{|l|}{ Type of school } \\
\hline Public & $0.4(0.1-1.6)$ & $0.0(0.4)$ & $0.3(0.4)$ & $-0.2(0.6)$ & $-0.3(0.5)$ \\
\hline \multicolumn{6}{|l|}{ Region of the country } \\
\hline South & $1.7(0.8-3.8)$ & $-0.4(0.3)$ & $-0.5(0.2)$ & $-0.1(0.4)$ & $-0.3(0.3)$ \\
\hline Mid-West & $1.2(0.6-2.2)$ & $-0.2(0.2)$ & $-0.2(0.2)$ & $0.4(0.3)$ & $-0.2(0.3)$ \\
\hline West & $1.4(0.7-2.9)$ & $-0.1(0.2)$ & $-0.3(0.2)$ & $0.1(0.4)$ & $-0.6^{*}(0.3)$ \\
\hline \multicolumn{6}{|l|}{ Urbanicity } \\
\hline Suburb & $1.1(0.5-2.4)$ & $0.2(0.3)$ & $0.2(0.3)$ & $-0.1(0.4)$ & $-0.1(0.4)$ \\
\hline Town & $1.0(0.4-2.1)$ & $-0.2(0.3)$ & $-0.1(0.3)$ & $-0.2(0.4)$ & $-0.4(0.3)$ \\
\hline Rural & $1.0(0.4-2.4)$ & $-0.3(0.3)$ & $-0.4(0.3)$ & $-0.3(0.4)$ & $-0.3(0.4)$ \\
\hline \multicolumn{6}{|l|}{ Racial/ethnic composition } \\
\hline$\%$ Black students & $1.4(0.4-4.8)$ & $-1.0 *(0.4)$ & $-0.6(0.4)$ & $0.7(0.6)$ & $-1.3 *(0.5)$ \\
\hline$\%$ Hispanic/Latinx students & $0.8(0.2-2.6)$ & $-0.2(0.4)$ & $-0.0(0.4)$ & $-0.3(0.6)$ & $0.2(0.5)$ \\
\hline \multicolumn{6}{|l|}{ Title I school } \\
\hline Yes & $1.0(0.5-1.8)$ & $0.2(0.1)$ & $0.0(0.2)$ & $-0.1(0.3)$ & $-0.2(0.3)$ \\
\hline$R^{2}$ & 0.084 & 0.184 & 0.148 & 0.075 & 0.132 \\
\hline
\end{tabular}

Second, teachers in US states in the West were less likely to indicate that they would refer students with depression for mental health services than teachers in the Northeast. There is limited previous research on this topic and results of prior studies have been mixed. For example, one prior study found that school-based mental health service receipt was higher in Southern states, as compared with states in the West, Midwest, and Northeast (Costello et al., 2014), whereas another study found that children in Southern states were less likely to access needed mental health services (Whitney \& Peterson, 2019). A study also found that there was a higher concentration of mental health providers in the Northeast than in other regions of the country (Ellis et al., 2009), which may influence teacher knowledge of mental health services 
Table 5 Ratings of oppositional defiant disorder seriousness, worry, commonness, and likelihood of referral

\begin{tabular}{|c|c|c|c|c|}
\hline Individual and school factors & $\begin{array}{l}\text { Serious } \\
M(\mathrm{SD})\end{array}$ & $\begin{array}{l}\text { Worry } \\
M(\mathrm{SD})\end{array}$ & $\begin{array}{l}\text { Common } \\
M(\mathrm{SD})\end{array}$ & $\begin{array}{l}\text { Referral } \\
M(\mathrm{SD})\end{array}$ \\
\hline \multicolumn{5}{|l|}{ Vignette factors } \\
\hline \multicolumn{5}{|l|}{ Vignette gender } \\
\hline Male & $7.9(1.4)$ & $8.1(1.4)$ & $4.1(2.2)$ & $8.2(1.9)$ \\
\hline Female & $7.9(1.4)$ & $8.1(1.5)$ & $4.2(2.3)$ & $8.0(2.0)$ \\
\hline \multicolumn{5}{|l|}{ Vignette severity } \\
\hline Moderate & $7.6(1.5)$ & $7.8(1.6)$ & $4.2(2.1)$ & $7.9(2.1)$ \\
\hline Severe & $8.2(1.3)^{*}$ & $8.4(1.3)^{*}$ & $4.1(2.3)$ & $8.3(1.9)$ \\
\hline \multicolumn{5}{|l|}{ Teacher factors } \\
\hline \multicolumn{5}{|l|}{ Gender } \\
\hline Male & $7.8(1.4)$ & $7.9(1.5)$ & $3.8(2.0)$ & $7.9(1.9)$ \\
\hline Female & $8.0(1.4)$ & $8.2(1.5)^{*}$ & $4.4(2.3)^{*}$ & $8.2(2.0)$ \\
\hline \multicolumn{5}{|l|}{ Ethnicity } \\
\hline Hispanic/Latinx & $8.1(1.7)$ & $8.2(1.5)$ & $3.7(2.6)$ & $8.6(1.8)$ \\
\hline Not Hispanic/Latinx & $7.9(1.4)$ & $8.1(1.5)$ & $4.2(2.2)$ & $8.1(2.0)$ \\
\hline \multicolumn{5}{|l|}{ Race } \\
\hline White/Caucasian & $7.9(1.4)$ & $8.1(1.5)$ & $4.1(2.2)$ & $8.1(2.0)$ \\
\hline Black/African American & $8.0(1.6)$ & $8.4(1.6)$ & $4.8(2.5)$ & $7.1(2.7)$ \\
\hline \multicolumn{5}{|l|}{ Years teaching } \\
\hline$<10$ years teaching & $7.8(1.3)$ & $8.1(1.3)$ & $4.2(2.2)$ & $7.8(1.9)$ \\
\hline $10+$ years teaching & $8.0(1.5)$ & $8.1(1.5)$ & $4.1(2.2)$ & $8.2(2.0)$ \\
\hline \multicolumn{5}{|l|}{ School factors } \\
\hline \multicolumn{5}{|l|}{ School level } \\
\hline Middle & $8.0(1.4)$ & $8.2(1.4)$ & $4.4(2.3)$ & $8.4(1.8)$ \\
\hline High & $7.9(1.4)$ & $8.0(1.5)$ & $4.0(2.2)^{*}$ & $7.9(2.2)^{*}$ \\
\hline \multicolumn{5}{|l|}{ Type of school } \\
\hline Public & $7.9(1.4)$ & $8.1(1.5)$ & $4.1(2.2)$ & $8.1(2.0)$ \\
\hline Other & $7.9(1.6)$ & $8.2(1.3)$ & $5.0(2.7)$ & $8.0(1.9)$ \\
\hline \multicolumn{5}{|l|}{ Region of the country } \\
\hline Northeast & $7.9(1.5)$ & $8.0(1.5)$ & $4.4(2.3)$ & $8.1(2.0)$ \\
\hline South & $7.9(1.2)$ & $8.2(1.4)$ & $4.1(2.1)$ & $8.2(1.8)$ \\
\hline Mid-West & $7.8(1.4)$ & $8.1(1.5)$ & $4.4(2.4)$ & $8.1(2.0)$ \\
\hline West & $8.2(1.4)$ & $8.2(1.4)$ & $3.7(2.0)$ & $8.1(2.2)$ \\
\hline \multicolumn{5}{|l|}{ Urbanicity } \\
\hline City & $7.8(1.5)$ & $8.1(1.5)$ & $4.4(2.4)$ & $8.1(2.0)$ \\
\hline Suburb & $7.9(1.5)$ & $8.2(1.5)$ & $3.9(2.1)$ & $8.2(1.9)$ \\
\hline Town & $8.2(1.2)$ & $8.3(1.3)$ & $3.7(1.9)^{1 *}$ & $8.3(1.8)$ \\
\hline Rural & $8.0(1.4)$ & $7.9(1.5)$ & $4.0(2.1)$ & $7.8(2.3)$ \\
\hline \multicolumn{5}{|l|}{ Racial/ethnic composition } \\
\hline $50 \%$ or more White & $8.0(1.4)$ & $8.1(1.5)$ & $3.9(2.1)$ & $8.2(1.9)$ \\
\hline $50 \%$ or more Black & $7.7(1.5)$ & $8.0(1.5)$ & $5.4(2.5)^{2 *}$ & $7.8(2.2)$ \\
\hline $50 \%$ or more Hispanic/Latinx & $8.0(1.3)$ & $8.2(1.3)$ & $4.1(2.3)$ & $8.4(1.6)$ \\
\hline No majority & $7.9(1.5)$ & $8.1(1.5)$ & $4.0(2.1)$ & $8.0(2.1)$ \\
\hline \multicolumn{5}{|l|}{ Title I school } \\
\hline Yes & $8.0(1.5)$ & $8.2(1.5)$ & $4.5(2.4)$ & $8.0(2.1)$ \\
\hline No & $7.9(1.4)$ & $8.0(1.5)$ & $4.2(2.1)$ & $8.1(2.1)$ \\
\hline
\end{tabular}

${ }^{1}$ Town $<$ City

${ }^{2}$ Majority Black $>$ All other groups

${ }^{*} p<.05$ based on $t$ test or one-way ANOVA 
Table 6 Oppositional Defiant Disorder: Association between individual teacher characteristics, school characteristics, and ratings of seriousness, worry, commonness, and likelihood of referral

\begin{tabular}{|c|c|c|c|c|}
\hline Teacher and school factors & $\begin{array}{l}\text { Serious } \\
B(\operatorname{SE} B)\end{array}$ & $\begin{array}{l}\text { Worry } \\
B(\operatorname{SE} B)\end{array}$ & $\begin{array}{l}\text { Common } \\
B(\mathrm{SE} B)\end{array}$ & $\begin{array}{l}\text { Referral } \\
B(\mathrm{SE} B)\end{array}$ \\
\hline \multicolumn{5}{|l|}{ Vignette factors } \\
\hline \multicolumn{5}{|l|}{ Vignette gender } \\
\hline Male & $0.6(0.2)$ & $0.0(0.2)$ & $0.1(0.3)$ & $0.2(0.3)$ \\
\hline \multicolumn{5}{|l|}{ Vignette severity } \\
\hline Severe & $0.5^{*}(0.2)$ & $0.4 *(0.2)$ & $-0.1(0.3)$ & $0.2(0.2)$ \\
\hline \multicolumn{5}{|l|}{ Teacher factors } \\
\hline \multicolumn{5}{|l|}{ Gender } \\
\hline Female & $0.3 *(0.2)$ & $0.4^{*}(0.2)$ & $0.8^{*}(0.3)$ & $0.3(0.3)$ \\
\hline \multicolumn{5}{|l|}{ Ethnicity } \\
\hline Hispanic/Latinx & $0.6(0.4)$ & $0.4(0.4)$ & $-0.2(0.6)$ & $0.8(0.6)$ \\
\hline \multicolumn{5}{|l|}{ Race } \\
\hline Black/African American & $0.2(0.4)$ & $0.4(0.4)$ & $0.0(0.6)$ & $-0.3(0.6)$ \\
\hline \multicolumn{5}{|l|}{ Years teaching } \\
\hline Years teaching (continuous) & $0.0 *(0.0)$ & $0.0(0.0)$ & $0.0(0.0)$ & $0.0(0.0)$ \\
\hline \multicolumn{5}{|l|}{ School factors } \\
\hline \multicolumn{5}{|l|}{ School level } \\
\hline High & $0.0(0.2)$ & $0.0(0.2)$ & $-0.6^{*}(0.3)$ & $-0.7 *(0.3)$ \\
\hline \multicolumn{5}{|l|}{ Type of school } \\
\hline Public & $-0.5(0.4)$ & $-0.2(0.4)$ & $0.5(0.6)$ & $0.4(0.6)$ \\
\hline \multicolumn{5}{|l|}{ Region of the country } \\
\hline South & $-0.2(0.3)$ & $-0.1(0.3)$ & $-0.1(0.4)$ & $-0.1(0.4)$ \\
\hline Mid-West & $-0.2(0.2)$ & $0.0(0.2)$ & $0.4(0.3)$ & $-0.1(0.3)$ \\
\hline West & $0.2(0.2)$ & $0.1(0.3)$ & $-0.4(0.4)$ & $-0.4(0.4)$ \\
\hline \multicolumn{5}{|l|}{ Urbanicity } \\
\hline Suburb & $0.4(0.3)$ & $0.4(0.3)$ & $-0.2(0.4)$ & $0.2(0.4)$ \\
\hline Town & $0.5(0.3)$ & $0.3(0.3)$ & $-0.1(0.4)$ & $-0.0(0.4)$ \\
\hline Rural & $0.2(0.3)$ & $-0.2(0.3)$ & $0.2(0.5)$ & $-0.2(0.4)$ \\
\hline \multicolumn{5}{|l|}{ Racial/ethnic composition } \\
\hline$\%$ Black students & $-0.5(0.4)$ & $-0.5(0.4)$ & $1.7 *(0.6)$ & $-0.1(0.6)$ \\
\hline$\%$ Hispanic/Latinx students & $-0.5(0.4)$ & $-0.5(0.4)$ & $-0.1(0.6)$ & $0.3(0.6)$ \\
\hline \multicolumn{5}{|l|}{ Title I school } \\
\hline Yes & $0.2(0.1)$ & $0.3(0.2)$ & $-0.0(0.3)$ & $-0.2(0.3)$ \\
\hline$R^{2}$ & 0.119 & 0.076 & 0.119 & 0.064 \\
\hline
\end{tabular}

$* p<.05$

and likelihood of referral. Future research on geographical variation in mental health service use and service availability may help to elucidate structural and contextual factors that influence the likelihood of students receiving services in their schools.

Third, in the current study, teachers in schools enrolling a majority of Black students rated depression as less serious and indicated that they were less likely to refer students for mental health services, as compared to teachers in schools with a lower proportion of Black students. We purposefully did not indicate student race or ethnicity in the vignette, as we were surveying teachers from schools that varied considerably in their racial and ethnic composition. As a result, we have only a general indicator of school composition, without further data on the context of the school or the race and ethnicity that the participant attributed to the student in the vignette. Nonetheless, results from the current study raise questions about how the composition of a teacher's school can contribute to disparities in mental health service access and reduce the likelihood that teachers will recommend a referral for mental health services.

Some previous research has found no racial/ethnic differences in use of school counseling services (Slade, 2002) or that racial/ethnic disparities in school service receipt attenuate when controlling for student symptom profile and gender (Langer et al., 2015). The findings here, however, accounted for both symptom profile and gender in the construction of the vignette manipulation and still found evidence that 
teachers working in schools with a higher proportion of Black students may be less likely to refer students for mental health services. Further, there was a significant interaction between the proportion of Black students in the school and vignette severity with teacher ratings of the commonness of ODD behaviors. Teachers rated severe ODD vignette behaviors as significantly more common when they worked in schools with a majority of Black students. Coupled with the prior finding for depression, this result suggests that even when presented with a standardized vignette absent information about student race, teachers in schools with a higher proportion of Black students were more likely to perceive that significant oppositional behaviors were common and were less likely to report they would refer students with depression for mental health services. These findings may reflect teacher racial biases related to mental health and mental health services (e.g., whether students behavior is assumed to indicate "trouble" vs. "needing support"), and racial biases in how teachers (who, in our sample, are primarily non-Latinx white) experience and respond to student behavior. Results also indicate the need to consider the role of teachers' referral decisions as situated within particular school contexts. As described above, prior studies have found that Black students are less likely than their white peers to access mental health services and more likely to receive punitive exclusionary discipline, even when engaging in the same behaviors (Gudiño et al., 2009; Kataoka et al., 2002; Skiba et al., 2011). Prior studies have found that school racial composition is associated with disciplinary decisions (Curran, 2016). The current study contributes to this existing literature by similarly finding that school racial composition may be important to mental health referral decisions. Additionally, it is possible that results reflect other factors that can influence teacher decision-making, such as systemic differences in funding for and availability of mental health services, as well as disparities in the availability of high-quality, and culturally and linguistically sustaining mental health services.

The current study has several limitations. The primary limitation is the use of vignettes. We elected to use vignettes because they allowed us to assess teachers' responses to a standard stimulus, thereby providing us with an opportunity to investigate identification and referral decisions that are difficult to precisely evaluate in the context of real cases. However, in reality, teachers might respond differently to students in their classes than they report they would respond to vignettes (Jerolmack \& Khan, 2014). Second, this study evaluated some of the most common forms of internalizing (depression) and externalizing (ODD) problems. However, we did not assess a broad range of disorders or teacher responses to comorbid disorders. Response to questions about anxiety or ADHD, for example, might provide different information about patterns in teacher referrals. Third, although we broadly and systematically sampled teachers across the U.S., only one-third of recruited teachers completed our survey. This response rate was higher than many other web surveys (Van Mol, 2017), however, it is possible that the teachers who chose to participate in this study were already the most attuned to student mental health. Fourth, we were limited in the school-level data available. Although we attempted to assess mental health service availability by asking respondents about the number of mental health providers in their schools, write-in comments from teachers on our survey led us to believe that many did not have this information or were not aware of the different roles and titles of providers in their school.

Despite limitations, this study provides data on teacher responses to student psychiatric disorders and their likelihood of referring students for mental health services across the U.S. Results regarding the racial composition of schools, in particular, contribute to a broad research base finding that Black students experience greater systemic barriers to accessing mental health services than white students and underscore the need for policy and practice interventions that engage stakeholders in increasing youth access to culturally and linguistically sustaining mental health services (Alegría et al., 2016). The current study also highlights a need for more research on how the availability and accessibility of mental health services varies across schools and may influence teacher decision-making around mental health supports and referrals. In particular, results raise important questions about regional variation and differences related to school urbanicity that might have implications for more effectively targeting school policy and intervention strategies. For example, whereas urban school districts may be able to build partnerships with community-based mental health centers (Pearrow et al., 2016), these resources are often less accessible for rural districts.

The study has several additional implications. First, in terms of teacher preparation, mental health training programs for secondary school teachers have been found to improve teacher mental health knowledge and attitudes (Anderson et al., 2019). These improvements may lead to more equitable access to services for students. Results of the current study, however, suggest that a single teacher preparation or training approach might not be equally effective for different school contexts. Just as trainings have been adapted to different cultural contexts (Crooks et al., 2018), adaptations may be needed for specific school communities, for example, to address regional variation in availability of mental health services and to integrate content related to systemic racial biases in the identification and referral process.

In addition, findings provide further support for the importance of school adoption of mental health screeners, which can systematically identify youth needing mental 
health services, without relying on teachers to determine which students require mental healthcare. Screeners ideally are paired with data on mental health service use (Green et al., 2021), so that schools can identify local disparities in service access among students who may need services, and then can actively address barriers to care. However, as noted above, most schools do not currently use universal screeners (Auerbach et al., 2020), indicating the need to continue to improve teacher preparation, even when screeners are available.

Finally, study results suggest several key areas for future research. Identifying contextual factors that influence teacher decision-making will be important both for understanding variability in service access and for improving teacher preparation. Further, rigorous research, particularly research integrating data from multiple levels of the school and social ecology, is needed to effectively determine how teachers inform pathways to student mental health service access. Ultimately, more deeply understanding how teachers serve in important identification and referral roles, particularly for youth who are underserved by the children's mental health services system, is necessary to enhance equitable service access.

Supplementary Information The online version contains supplementary material available at https://doi.org/10.1007/s12310-021-09491-1.

Acknowledgements This study was supported by a National Institute of Mental Health grant (K01MH085710) to J. Green. We are grateful for assistance from the National Association of School Psychologists to conduct this research. We are also thankful for the contributions of members of our research team including Javier Guzmán, Shannon Gribben, and Suzanne Vinnes.

Funding The authors have no financial relationships relevant to this article to disclose.

\section{Declarations}

Conflict of interest The authors have no conflict of interest to disclose.

\section{References}

Aitken, M., Martinussen, R., \& Tannock, R. (2017). Incremental validity of teacher and parent symptom and impairment ratings when screening for mental health difficulties. Journal of Abnormal Child Psychology, 45(4), 827-837.

Alegría, M., Green, J. G., McLaughlin, K. A., \& Loder, S. (2016). Disparities in child and adolescent mental health and mental health services in the US. William T. Grant Foundation.

Alegría, M., Lin, J. Y., Green, J. G., Sampson, N. A., \& Kessler, R. C. (2012). Role of referrals in mental health service disparities for racial and ethnic minority youth. Journal of the American Academy of Child \& Adolescent Psychiatry, 51(7), 703-711.

American Psychiatric Association. (2013). Diagnostic and statistical manual of mental disorders (5th ed.). Author.
Anderson, M., Werner-Seidler, A., King, C., Gayed, A., Harvey, S. B., \& O'Dea, B. (2019). Mental health training programs for secondary school teachers: A systematic review. School Mental Health, 11(3), 489-508.

Auerbach, E. R., Chafouleas, S. M., Briesch, A. M., \& Long, S. J. (2020). Exploring the alignment of behavior screening policies and practices in US public school districts. Journal of School Health, 90(4), 264-270.

Benjet, C., Borges, G., Mendez, E., Albor, Y., Casanova, L., Orozco, R., Curiel, T., Fleiz, C., \& Medina-Mora, M. E. (2016). Eightyear incidence of psychiatric disorders and service use from adolescence to early adulthood: Longitudinal follow-up of the mexican adolescent mental health survey. European Child \& Adolescent Psychiatry, 25(2), 163-173.

Bradshaw, C. P., Buckley, J. A., \& Ialongo, N. S. (2008). Schoolbased service utilization among urban children with early onset educational and mental health problems: The squeaky wheel phenomenon. School Psychology Quarterly, 23(2), 169-186.

Briesch, A. M., Chafouleas, S. M., \& Chaffee, R. K. (2018). Analysis of state-level guidance regarding school-based, universal screening for social, emotional, and behavioral risk. School Mental Health, 10(2), 147-162.

Brown, J. D., Wissow, L. S., Gadomski, A., Zachary, C., Bartlett, E., \& Horn, I. (2006). Parent and teacher mental health ratings of children using primary-care services: Interrater agreement and implications for mental health screening. Ambulatory Pediatrics, 6(6), 347-351.

Bruhn, A. L., Woods-Groves, S., \& Huddle, S. (2014). A preliminary investigation of emotional and behavioral screening practices in $\mathrm{K}-12$ schools. Education and Treatment of Children, 37(4), 611-634.

Burns, B. J., Costello, E. J., Angold, A., Tweed, D., Stangl, D., Farmer, E. M., \& Erkanli, A. (1995). Children's mental health service use across service sectors. Health Affairs, 14(3), 147-159.

Chang, D. F., \& Sue, S. (2003). The effects of race and problem type on teachers' assessments of student behavior. Journal of Consulting and Clinical Psychology, 71, 235-242.

Chavez, L. M., Shrout, P. E., Alegría, M., Lapatin, S., \& Canino, G. (2010). Ethnic differences in perceived impairment and need for care. Journal of Abnormal Child Psychology, 38(8), 1165-1177.

Costello, E. J., He, J. P., Sampson, N. A., Kessler, R. C., \& Merikangas, K. R. (2014). Services for adolescents with psychiatric disorders: 12 -month data from the national comorbidity survey- adolescent. Psychiatric Services, 65(3), 359-366.

Cotton, S. M., Wright, A., Harris, M. G., Jorm, A. F., \& McGorry, P. D. (2006). Influence of gender on mental health literacy in young Australians. Australian and New Zealand Journal of Psychiatry, 40(9), 790-796.

Crooks, C. V., Lapp, A., Auger, M., van der Woerd, K., Snowshoe, A., Rogers, B. J., Tsuruda, S., \& Caron, C. (2018). A feasibility trial of mental health first aid first nations: Acceptability, cultural adaptation, and preliminary outcomes. American Journal of Community Psychology, 61(3-4), 459-471.

Curran, F. C. (2016). Estimating the effect of state zero tolerance laws on exclusionary discipline, racial discipline gaps, and student behavior. Educational Evaluation and Policy Analysis, 38(4), 647-668.

De Los Reyes, A., Augenstein, T. M., Wang, M., Thomas, S. A., Drabick, D. A. G., Burgers, D. E., \& Rabinowitz, J. (2015). The validity of the multi-informant approach to assessing child and adolescent mental health. Psychological Bulletin, 141(4), 858-900.

Duong, M. T., Bruns, E. J., Lee, K., Cox, S., Coifman, J., Mayworm, A., \& Lyon, A. R. (2021). Rates of mental health service utilization by children and adolescents in schools and other common 
service settings: A systematic review and meta-analysis. Administration and Policy in Mental Health and Mental Health Services Research, 48, 42-439.

Ellis, A. R., Konrad, T. R., Thomas, K. C., \& Morrissey, J. P. (2009). County-level estimates of mental health professional supply in the United States. Psychiatric Services, 60(10), 1315-1322.

Green, J. G., Guzmán, J., Didaskalou, E., Harbaugh, A. G., Segal, N., \& LaBillois, J. (2018). Teacher identification of student emotional and behavioral problems and provision of early supports: A vignette-based study. Journal of Emotional and Behavioral Disorders, 26(4), 225-242.

Green, J. G., Keenan, J. K., Guzmán, J., Vinnes, S., Holt, M., \& Comer, J. S. (2017). Teacher perspectives on indicators of adolescent social and emotional problems. Evidence-Based Practice in Child and Adolescent Mental Health, 2(2), 96-110.

Green, J. G., Oblath, R., Schneider, S. K., \& Miller, M. (2021). Assessing adolescent mental health service use: Developing the Adolescent Mental Health Support Scale (AMHSS). School Mental Health. https://doi.org/10.1007/s12310-021-09460-8

Green, M. T., Clopton, J. R., \& Pope, A. W. (1996). Understanding gender differences in referral of children to mental health services. Journal of Emotional and Behavioral Disorders, 4(3), 182-190.

Gudiño, O. G., Lau, A. S., Yeh, M., McCabe, K. M., \& Hough, R. L. (2009). Understanding racial/ethnic disparities in youth mental health services: Do disparities vary by problem type? Journal of Emotional and Behavioral Disorders, 17(1), 3-16.

Gulliver, A., Griffiths, K. M., \& Christensen, H. (2010). Perceived barriers and facilitators to mental health help-seeking in young people: A systematic review. BMC Psychiatry, 10(1), 1-9.

Jerolmack, C., \& Khan, S. (2014). Talk is cheap: Ethnography and the attitudinal fallacy. Sociological Methods \& Research, 43(2), 178-209.

Jorm, A. F., Kitchener, B. A., Sawyer, M. G., Helen, S., \& Stefan, C. (2010). Mental health first aid training for high school teachers: A cluster randomized trial. BMC Psychiatry, 10(1), 51.

Kataoka, S. H., Zhang, L., \& Wells, K. B. (2002). Unmet need for mental health care among U.S. children: Variation by ethnicity and insurance status. American Journal of Psychiatry, 159(9), $1548-1555$.

Kessler, R. C., Berglund, P., Demler, O., Jin, R., Merikangas, K. R., \& Walters, E. E. (2005). Lifetime prevalence and age-of-onset distributions of DSM-IV disorders in the National Comorbidity Survey Replication. Archives of General Psychiatry, 62(6), 593-602.

Kovess-Masfety, V., Van Engelen, J., Stone, L., Otten, R., Carta, M. G., Bitfoi, A., Koc, C., Goelitz, D., Lesinskiene, S., Mihova, Z., Fermanian, C., \& Husky, M. (2017). Unmet need for specialty mental health services among children across Europe. Psychiatric Services, 68(8), 789-795.

Langer, D. A., Wood, J. J., Wood, P. A., Garland, A. F., Landsverk, J., \& Hough, R. L. (2015). Mental health service use in schools and non-school-based outpatient settings: Comparing predictors of service use. School Mental Health, 7(3), 161-173.

Lapatin, S., Gonçalves, M., Nillni, A., Chavez, L., Quinn, R. L., Green, A., \& Alegría, M. (2012). Lessons from the use of vignettes in the study of mental health service disparities. Health Services Research, 47(3), 1345-1362.

Lau, A. S., McCabe, K. M., Yeh, M., Garland, A. F., Hough, R. L., \& Landsverk, J. (2003). Race/ethnicity and rates of self-reported maltreatment among high-risk youth in public sectors of care. Child Maltreatment, 8(3), 183-194.

Leaf, P. J., Alegria, M., Cohen, P., Goodman, S. H., Horwitz, S. M., Hoven, C. W., Narrow, W. E., Vaden-Kiernan, M., \& Regier, D. A. (1996). Mental health service use in the community and schools: Results from the four-community MECA study. Journal of the American Academy of Child \& Adolescent Psychiatry, 35(7), 889-897.
Loades, M. E., \& Mastroyannopoulou, K. (2010). Teachers recognition of children's mental health problems. Child and Adolescent Mental Health, 15(3), 150-156.

McLean, D., Eklund, K., Kilgus, S. P., \& Burns, M. K. (2019). Influence of teacher burnout and self-efficacy on teacher-related variance in social-emotional and behavioral screening scores. School Psychology, 34(5), 503.

Maughan, B., Rowe, R., Messer, J., Goodman, R., \& Meltzer, H. (2004). Conduct disorder and oppositional defiant disorder in a national sample: Developmental epidemiology. Journal of Child Psychology and Psychiatry, 45(3), 609-621.

Merikangas, K. R., He, J. P., Burstein, M., Swanson, S. A., Avenevoli, S., Cui, L., Benjet, C., Georgiades, K., \& Swendsen, J. (2010a). Lifetime prevalence of mental disorders in US adolescents: Results from the national comorbidity survey replication-adolescent supplement (NCS-A). Journal of the American Academy of Child and Adolescent Psychiatry, 49(10), 980-989.

Merikangas, K. R., He, J. P., Burstein, M., Swendsen, J., Avenevoli, S., Case, B., Georgiades, K., Heaton, L., Swanson, S., \& Olfson, M. (2011). Service utilization for lifetime mental disorders in US adolescents: Results of the national comorbidity survey-adolescent supplement (NCS-A). Journal of the American Academy of Child and Adolescent Psychiatry, 50(1), 32-45.

Merikangas, K. R., He, J., Brody, D., Fisher, P. W., Bourdon, K., \& Koretz, D. S. (2010b). Prevalence and treatment of mental disorders among US children in the 2001-2004 NHANES. Pediatrics, 125(1), 75-81.

Nguyen, L., Huang, L. N., Arganza, G. F., \& Liao, Q. (2007). The influence of race and ethnicity on psychiatric diagnoses and clinical characteristics of children and adolescents in children's services. Cultural Diversity and Ethnic Minority Psychology, 13(1), 18-25. https://doi.org/10.1037/1099-9809.13.1.18

Nock, M. K., Kazdin, A. E., Hiripi, E., \& Kessler, R. C. (2007). Lifetime prevalence, correlates, and persistence of oppositional defiant disorder: Results from the National Comorbidity Survey Replication. Journal of Child Psychology and Psychiatry, 48(7), 703-713.

Pearcy, M. T., Clopton, J. R., \& Pope, A. W. (1993). Influences on teacher referral of children to mental health services: Gender, severity, and internalizing versus externalizing problems. Journal of Emotional and Behavioral Disorders, 1(3), 165-169. https:// doi.org/10.1177/106342669300100304

Pearrow, M. M., Amador, A., \& Dennery, S. (2016). Boston Public Schools' Comprehensive Behavioral Health Model. Communiqué, $45(3), 1-20$.

Reavley, N. J., McCann, T. V., \& Jorm, A. F. (2012). Mental health literacy in higher education students. Early Intervention in Psychiatry, 6(1), 45-52.

Reinke, W. M., Stormont, M., Herman, K. C., Puri, R., \& Goel, N. (2011). Supporting children's mental health in schools: Teacher perceptions of needs, roles, and barriers. School Psychology Quarterly, 26(1), 1-13.

Ringeisen, H., Henderson, K., \& Hoagwood, K. (2003). Context matters: Schools and the "research to practice gap" in children's mental health. School Psychology Review, 32(2), 153-168.

Shaffer, D., Gould, M. S., Brasic, J., Ambrosini, P., Fisher, P., Bird, H., \& Aluwahlia, S. (1983). A children's global assessment scale (CGAS). Archives of General Psychiatry, 40(11), 1228-1231.

Sheppard, R., Deane, F. P., \& Ciarrochi, J. (2018). Unmet need for professional mental health care among adolescents with high psychological distress. Australian \& New Zealand Journal of Psychiatry, 52(1), 59-67.

Skiba, R. J., Horner, R. H., Chung, C. G., Rausch, M. K., May, S. L., \& Tobin, T. (2011). Race is not neutral: A national investigation of African American and Latino disproportionality in school discipline. School Psychology Review, 40(1), 85-107. 
Slade, E. P. (2002). Effects of school-based mental health programs on mental health service use by adolescents at school and in the community. Mental Health Services Research, 4, 151-166.

Splett, J. W., Raborn, A., Brann, K., Smith-Millman, M. K., Halliday, C., \& Weist, M. D. (2020). Between-teacher variance of students' teacher-rated risk for emotional, behavioral, and adaptive functioning. Journal of School Psychology, 80, 37-53.

State, T. M., Kern, L., Starosta, K. M., \& Mukherjee, A. D. (2011). Elementary pre-service teacher preparation in the area of social, emotional, and behavioral problems. School Mental Health, 3(1), $13-23$.

Stiffman, A. R., Pescosolido, B., \& Cabassa, L. J. (2004). Building a model to understand youth service access: The gateway provider model. Mental Health Services Research, 6(4), 189-198.

Taie, S., \& Goldring, R. (2017). Characteristics of public elementary and secondary school teachers in the United States: Results from the 2015-16 national teacher and principal survey first look (NCES 2017-072). U.S. Department of Education.

United States Department of Education. (2021). Frequently asked questions elementary and secondary school emergency relief programs governor's emergency education relief programs. U.S. Department of Education.
Van Mol, C. (2017). Improving web survey efficiency: The impact of an extra reminder and reminder content on web survey response. International Journal of Social Research Methodology: Theory \& Practice, 20(4), 317-327.

Wagner, M., Friend, M., Bursuck, W. D., Kutash, K., Duchnowski, A. J., Sumi, W. C., \& Epstein, M. H. (2006). Educating students with emotional disturbances: A national perspective on school programs and services. Journal of Emotional and Behavioral Disorders, 14(1), 12-30.

Weisz, J. R., Suwanlert, S., Chaiyasit, W., Weiss, B., Walter, B. R., \& Anderson, W. W. (1988). Thai and American perspectives on over- and undercontrolled child behavior problems: Exploring the threshold model among parents, teachers, and psychologists. Journal of Consulting and Clinical Psychology, 56(4), 601-609.

Whitney, D. G., \& Peterson, M. D. (2019). US national and state-level prevalence of mental health disorders and disparities of mental health care use in children. JAMA Pediatrics, 173(4), 389-391.

Publisher's Note Springer Nature remains neutral with regard to jurisdictional claims in published maps and institutional affiliations. 